\title{
An Investigation of Phone Upgrades in Remote Community Cellular Networks
}

\author{
Kushal Shah \\ University of Washington \\ kushals@uw.edu \\ Shaddi Hasan \\ Facebook \\ shasan@fb.com
}

\author{
Philip Martinez \\ University of the Philippines Diliman \\ philip.martinez@up.edu.ph \\ Cedric Festin \\ University of the Philippines Diliman \\ cmfestin@up.edu.ph
}

\author{
Emre Tepedelenlioglu \\ Facebook \\ emre@fb.com
}
Joshua Blumenstock
University of California, Berkeley
jblumenstock@berkeley.edu

\author{
Josephine Dionisio \\ University of the Philippines Diliman \\ jcdionisio@up.edu.ph
}

\author{
Kurtis Heimerl \\ University of Washington/Facebook \\ kheimerl@cs.washington.edu
}

\begin{abstract}
In the last decade, billions of people worldwide have upgraded from basic $2 \mathrm{G}$ feature phones to data-enabled $4 \mathrm{G}$ smartphones. In most cases, people upgrade in areas with $4 \mathrm{G}$ coverage (typically cities and large towns), but increasingly, people choose to upgrade in areas that only have $2 \mathrm{G}$ coverage or no cellular coverage at all. This counterintuitive behavior - upgrading your phone despite living in an area that does not actively support many of the features of that new device - is the focus of this work.

We investigate the rates and reasons for $4 \mathrm{G}$ upgrades and adoption in two extremely remote areas in Indonesia and the Philippines. Our mixed-methods approach combines the quantitative analysis of several years of mobile phone registration logs with the qualitative analysis of multiple interviews in one of these communities. We learn that users are rapidly switching from $2 \mathrm{G}$ to $4 \mathrm{G}$ technology and skipping $3 \mathrm{G}$ entirely; the data suggest that these villages will soon have sufficient $4 \mathrm{G}$ phone adoption to justify the investment required to upgrade base stations to $4 \mathrm{G}$ technology. The interviews suggest people are making these switches primarily to support consumption of media such as games, videos, and music. Similarly, users switch devices because of damage, often leading to downgrades to more resilient feature phones. We also find that, despite the general value seen in more modern $4 \mathrm{G}$ phones, $2 \mathrm{G}$ phones are more shared and more active on the network.
\end{abstract}

\section{ACM Reference Format:}

Kushal Shah, Philip Martinez, Emre Tepedelenlioglu, Shaddi Hasan, Cedric Festin, Joshua Blumenstock, Josephine Dionisio, and Kurtis Heimerl. 2017. An Investigation of Phone Upgrades in Remote Community Cellular Networks. In Proceedings of (ICTD '17). ACM, New York, NY, USA, 12 pages. https://doi.org/10.1145/3136560.3136569

\footnotetext{
Permission to make digital or hard copies of part or all of this work for personal or classroom use is granted without fee provided that copies are not made or distributed for profit or commercial advantage and that copies bear this notice and the full citation on the first page. Copyrights for third-party components of this work must be honored. For all other uses, contact rightsreview@acm.org.

ICTD '17, November 16-19, 2017, Lahore, Pakistan

(C) 2017 Copyright held by the owner/author(s) Publication rights licensed to ACM. ACM ISBN 978-1-4503-5277-2/17/11.
}

https://doi.org/10.1145/3136560.3136569

\section{INTRODUCTION}

For billions of people, the primary technology for accessing the cellular network is a $2 \mathrm{G}$ feature phone [14]. However, as telecoms invest heavily in $3 \mathrm{G}$ and $4 \mathrm{G}$ infrastructure, it is becoming clear that the smartphone will be the dominant technology of the future. In most dense urban areas, the three network types $-2 \mathrm{G}, 3 \mathrm{G}$, and $4 \mathrm{G}$ - already operate simultaneously and users can upgrade as their devices and disposable income allows.

In rural areas, however, it is less clear if and how this transition will occur. Particularly in areas without existing coverage, operators face a conundrum in deciding whether to deploy $2 \mathrm{G}$ networks that are cheap and broadly compatible (but may soon be obsolete), or $3 \mathrm{G}$ or $4 \mathrm{G}$ networks that are modern and expensive (and where they may never recoup their initial investment). Part of this ambiguity stems from the lack of reliable data on how feature phones and smartphones are used in remote communities, and when and why subscribers typically upgrade their devices.

The goal of this study is to develop an understanding of mobile phone upgrade behavior in rural areas. We focus our analysis on two rural communities in the Philippines and Indonesia that first received cellular network access in 2013 and 2016, respectively. We develop a quantitative picture of phone upgrade behavior through the analysis of a large volume of longitudinal log data collected by the cellular network operator. Specifically, we analyze the Type Allocation Codes (TACs) logs, which provide a detailed record of the phone models used by each user, over time, in each community. We complement this quantitative analysis with follow-up qualitative field work in the Philippines. Through fifteen semi-structured interviews with individuals who recently upgraded their phones, we add some texture and insight into the stories behind the data.

Our primary findings are that:

- $4 \mathrm{G}$ phones are common (17.9\% in Indonesia and $22.5 \%$ in the Philippines), even though the local network does not support $4 \mathrm{G}$ data,

- $4 \mathrm{G}$ phone adoption has accelerated dramatically on both networks (more than 2x year-over-year on both networks),

- Most phone upgrades are between $2 \mathrm{G}$ and $4 \mathrm{G}$ (93.62\% for Indonesia and $81.53 \%$ for the Philippines), skipping $3 \mathrm{G}$ almost entirely, 
- Users of $4 \mathrm{G}$ phones were less active on the $2 \mathrm{G}$ network than users of $2 \mathrm{G}$ only phones,

- People share their $2 \mathrm{G}$ phones nearly 3 times more than their $4 \mathrm{G}$ phones,

- Those upgrading to $4 \mathrm{G}$ phones were usually young and often handed their old phones to family members, and

- A primary reason people upgraded to a $4 \mathrm{G}$ phone was to be able to better play media.

From these findings, we conclude that telecoms should focus on only $2 \mathrm{G}$ and $4 \mathrm{G}$ networks in rural areas. Our back-of-the-envelope calculations indicate that operators could profitably deploy $4 \mathrm{G}$ networks (rather than $2 \mathrm{G}$ ) in these communities within the next two years. Finally, we discuss several mechanisms to accelerate $4 \mathrm{G}$ adoption in rural areas.

\section{RELATED WORK}

\subsection{Community Cellular}

This paper leverages data from two community cellular networks (CCNs) installed in remote parts of the world. CCNs [16] are locally owned and operated cellular networks. There are a number of these operating in the world now, with Rhizomatica [26] being the largest. Two other networks include the Papuacom Network [17] in Indonesia and the Kwiizya network in Zambia [1, 34]. There are three key things about CCNs: first, they are logically separate from existing telecoms and thus provide a unique sandbox for experiments; second, they are operated by local agents and; third, they usually operate in rural areas without traditional cellular coverage.

\subsection{Mobile Adoption and Use}

There is a rich literature on technology adoption which we do not attempt to survey here [cf. 27]. Venkatesh et al. [33] develop a framework that helps structure our thinking of mobile adoption in this context, particularly with respect to facilitating conditions, social influence, and performance expectancy. Here, facilitating conditions, which indicate "the degree to which an individual believes that an organizational and technical infrastructure exists to support use of the system," are relatively weak in these villages - in both cases there is no $3 \mathrm{G}$ or $4 \mathrm{G}$ coverage in the surveyed communities. Regarding social influence, "the degree to which an individual perceives that important others believe he or she should use the new system," is perhaps more limited than in urban areas, although we do observe nearby ads suggesting users upgrade. Lastly, users were also keenly aware of performance expectancy, "the degree to which an individual believes that using the system will help him or her to attain gains in job performance," where job performance would be observed user activity like watching movies or learning new skills.

There is also work more specifically focused on mobile phone adoption. Van Biljon et al. [32] provide a thorough review. The authors create a framework for viewing mobile phone adoption through either physical, social, mental, or technological contexts. Our work focuses on the technological ( $2 \mathrm{G}$ vs. $4 \mathrm{G}$ ), social (media drives for smartphone adoption) and physical (rural areas) contexts.

\subsection{Entertainment as Development}

One of the key findings from this work is that entertainment is driving $4 \mathrm{G}$ cellular adoption. This is supported by previous studies that show the importance of entertainment in promoting investment and the use of ICTs. Smyth et al. [30] showed that users in the slums of Bengaluru build complex bluetooth-based networks for media sharing. Raza et al. [25] built a system utilizing entertainment (specifically viral voice modifying) to direct users to a voice job board. Our work supports these results and shows that entertainment is similarly important for promoting rural access.

\subsection{Cellular Records}

Finally, this study relates to a growing body of research using cellular records to understand processes of development. Examples include the use of mobile phone data to measure poverty [2], understand the impacts of mobile money [4], and more generally model human behavior $[3,12]$. The vast majority of such work uses call data records (CDRs), which are captures of metadata from phone calls and text messages.

Our use of Type Allocation Codes (TACs) is somewhat novel. Two major works have explored this data source. Heimerl et al. [18] investigated smartphone adoption in an Indonesian community cellular network and found that the adoption rate was in line with the rest of the country and SMS usage was higher on smartphones. We use this as justification that the analysis of community cellular networks could potentially be generalized to non-community networks. Ahmad et al, [1] did a similar analysis on a regional scale, gathering TACs from the Pakistani province of the Punjab. From that dataset they were able to measure operating system versions and capabilities of the phones. There are two key differences from our work. First, Ahmad's work is a snapshot of the country and has no longitudinal components, required for measuring smartphone adoption. Second, it is a trace from a mostly urban province and would not assist in exploring the possibilities in rural cellular installations.

\section{CONTEXT}

The contexts we study are rural communities in the Philippines and Indonesia. While global adoption of smartphones is tracked closely by several industry groups, very little information exists on rural adoption - this is a key focus and motivation for this study. Broadly, GSMA Intelligence [19] reports that the overall rate of smartphone adoption in the Philippines in 2014 was $28 \%$, and a similar estimate of $30 \%$ was made by IDC in 2016 [8]. For Indonesia, the GSMA reports smartphone penetration of 47\% [14]. While both estimates are not extremely different from our combined $3 \mathrm{G}$ and $4 \mathrm{G}$ observations, neither source disaggregates smartphone adoption across rural and urban boundaries.

In this section, we describe the two communities of study in this project: Barangay San Andres in Luzon, Philippines, and Bokondini in Papua, Indonesia. It's worth noting that the study is not comparing the two sites against each other (as their differences are many) and it is instead seeking findings that generalizes across both (as their commonalities include having community cellular networks and being rural). 


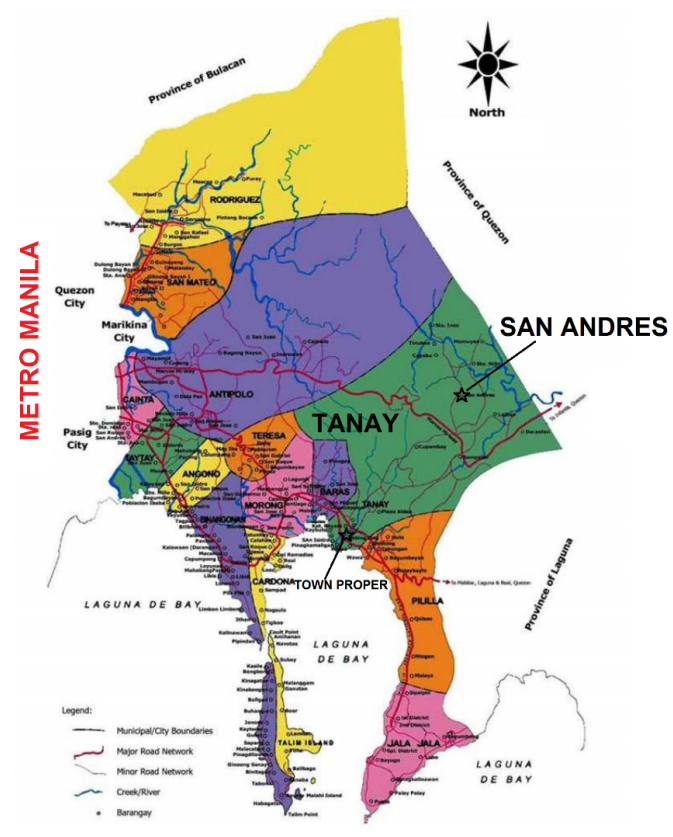

Figure 1: The Location of Barangay San Andres

\subsection{Barangay San Andres}

Barangay San Andres is a rural Barangay (a barangay is the basic political unit in the Philippines) within Tanay, which is a first class municipality in Rizal province (Figure 1). Barangay San Andres is located within the watershed of the Upper Marikina River Basin Protected Landscape and has a generally mountainous terrain. It is relatively near (approximately $60 \mathrm{~km}$ away) Quezon City, which is a highly urbanized city that was once designated as the nation's capital. It is also within easy commuting distance (around $30 \mathrm{~km}$ away) to Tanay Town proper. Tricycles (three-wheeled motorcycles) are the main mode of public transportation in and out of the Barangay.

The total population of Barangay San Andres is 2,145, with 481 households as of December 2016. It is composed of 1,122 males and 1,023 females. There are approximately 228 students studying at the elementary school located within the Barangay, while 19 students are enrolled at the kindergarten within the Barangay.

3.1.1 Industry. Barangay San Andres is largely rural, with stretches of farmlands, grazing areas for livestock, mountainous areas, and geologic formations that attract tourists and sports enthusiasts. As such, the sources of income include farming, tourism, and the seasonal production of woven split bamboo mats (sawali). San Andres features tracts of privately-owned farms where locals are employed as farmers and caretakers. Major cash crops include rice, cassava, banana, and papaya.

Potential tourist attractions abound in San Andres, such as the Sangab Cave, Kay-Ibon Falls, and Kanabuan Falls. The Barangay also serves as the jump-off point for Mt. Batalusong. Hikers are required to secure local tour guides from amongst San Andres. Recent efforts of the Tanay Local Government aim to institutionalize
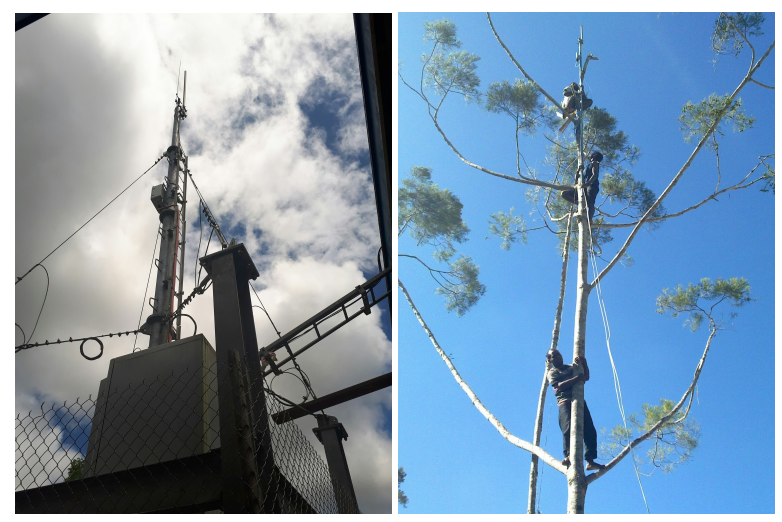

Figure 2: The two cellular networks, San Andres (left), Bokondini (right)

the tourism activities in the Barangay through further development of tourist attractions and bolstering of the local tourism industry.

3.1.2 Infrastructure. San Andres does not have access to an electricity grid, but instead has a communal generator that operates for a limited duration each day. Billing for this service is organized in an ad-hoc manner with a member of the local government canvassing the community at night to see who is using power. Some households have their own generator or use solar power. Deep wells, aside from the small streams, are the main source of water. There is no Internet access available in the community and instead users travel outside to make use of free or inexpensive wifi elsewhere.

3.1.3 Cellular Network. A community cellular network using the CommunityCellularManager [11] software was installed in San Andres in February 2016 (see Figure 2). The equipment supports voice and SMS only and is not yet Internet-capable. The base station is solar-powered to compensate for the variance in local power generation. Subscribers are required to purchase a local SIM (branded TM Barangay) to connect to the local cellular network. The presence of cellular signal has changed the way locals do business. The tourism industry got a boost, as tour guides are now capable of contacting clients and maintaining a Facebook page with their local cell numbers. The network was installed in partnership with Globe Telecom and uses their satellite backhaul.

\subsection{Bokondini, Papua, Indonesia}

Bokondini (Figure 3), our second data collection site, is a small rural community situated in the highlands of Papua, a mountainous region traversing the center of the island of Papua in Southeast Asia. It is approximately four hours drive from the regional capital of Wamena, which is only accessible by flying from other parts of Papua. The road to Bokondini is paved, though it involves one serious river crossing that requires a 4-wheel drive truck.

Bokondini is an established community of approximately 1500 people who are primarily indigenous Papuans. Unfortunately, there is no official census of the region, leaving only informal measurements. The community itself consists of five major groups: First, there are three local churches (all Protestant) each with their own local buildings. These churches are run primarily by, and service, 
the local Papuan Christian community. Outside of these churches, there are two local subcommunities for non-Papuan Indonesians (Pendatang), the police and the military. The police handle local community matters and the military maintain a small base to limit local participation in the Free Papua movement.

3.2.1 Industry. The region's main economic activity is subsistence agriculture. One particularly notable cash crop is pineapples, which are known to be good in Bokondini. In the morning, vendors bring pineapples by taxi to major markets in Wamena. Apart from agriculture, there are a few stores and a large amount of political and governmental activity as the village transitions into a regional district.

3.2.2 Infrastructure. Bokondini has no community infrastructure, including no traditional cellular coverage. Local organizations and individuals operate decentralized water, power, and Internet access solutions. There is an airstrip which is used by the Missionary Air Force for emergencies and occasional resupplies. There is also a road running to Wamena, which is the closest major city with existing power, water, and cellular network access.

3.2.3 Cellular Network. In 2013, as part of early work on community cellular networks, a local cellular network was installed in Bokondini [17]. The network is operated by a local ISP in Wamena and managed by a primary school within the community (which is summarily owned and operated by one of the local Papuan churches). The network tower, a tree, is shown in Figure 2. The network has profitably operated for the following three years without any major hiccups. In late 2016, the network operator decided to change their pricing to a monthly base fee with usage on top, which caused a large culling of underused accounts. This dropped the number of subscribers in the system. This network, like the Philippines network, is a $2 \mathrm{G}$ voice and SMS only network utilizing the CommunityCellularManager software. Data remains unavailable to subscribers. It is backhauled over a a satellite terminal to Hong Kong and uses phone numbers from the online provider Nexmo.

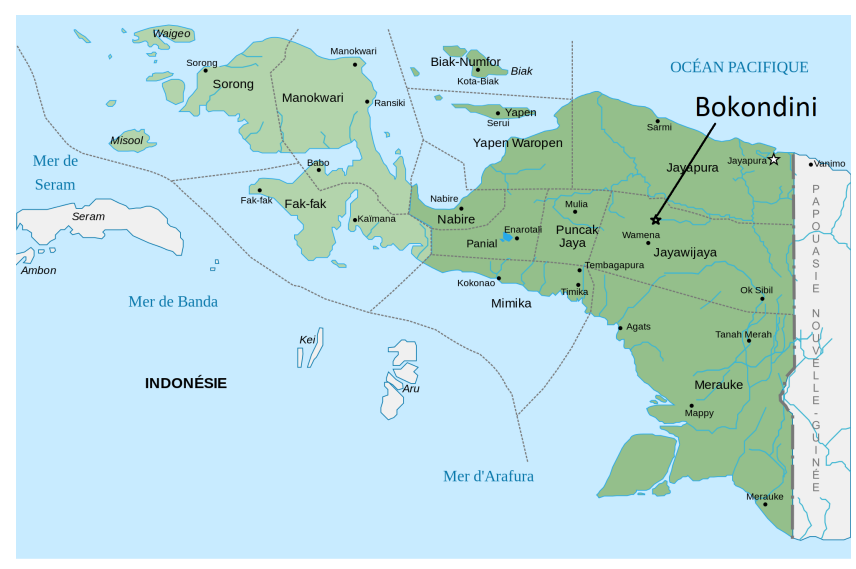

Figure 3: The Location of Bokondini, Papua
Table 1: Fields derived from TAC Data

\begin{tabular}{ll}
\hline Field & Example \\
\hline Marketing Name & iPhone A1203 \\
Manufacturer & Apple Inc \\
Radios & GSM 1800, GSM 1900, GSM 900, GSM850 \\
Model Name & iPhone A1203 \\
Operating System & iOS \\
Device Type & Handheld \\
Radios & Bluetooth 2.0 \\
Manufactured & June 2007 \\
\hline
\end{tabular}

\section{DATA AND METHODS}

The primary data analyzed in this work is logon ("camp" in cellular terminology) records from two rural community cellular networks. We conduct a series of quantitative analyses of this dataset to learn more about phone adoption behavior, including specific technologies and rates of adoption, across the two communities. Following these results we drive deeper by conducting a series of qualitative interviews inside of one of the communities to explore why and how people are adopting new devices.

\subsection{Quantitative Data and Analysis}

The principle item of data being analyzed in this work is the Type Allocation Code or TAC of the mobile phone subscribers. The TAC is a subset of the International Mobile Equipment Identity (IMEI), which is akin to the serial number of a cellular phone. An IMEI is a fifteen digit code formatted as follows:

$$
A A-B B B B B B-C C C C C C-D
$$

Where the $A$ and $B$ sections specify the serial number of that specific phone, the $\mathrm{C}$ block specifies the TAC and the $\mathrm{D}$ digit is a checksum. From an IMEI, we can indentify the unique phone (using the serial number) and the model of phone used (using the TAC).

To track upgrades of phones we also collected the International Mobile Subscriber Identity (IMSI) from all phones that attempt to attach to the towers. The IMSI uniquely identifies a SIM card, and when paired with the IMEI, provides both unique identifiers for a SIM and phone pair. When a single device (IMEI) is observed with multiple SIM cards (IMSI), we call this a "shared" phone, but note that this is likely an underestimate of actual phone sharing, since we cannot tell when two people share a SIM card.

From the TAC data, we cross-reference with online databases to infer characteristics of the mobile phones themselves. The key fields, shown in Table 1, make it possible to understand the features and affordances of the phones in our network. We also sourced the manufacturing date of the devices by looking up each on the Internet (usually GSMArena [15]). We were able to find the manufacturing date of most $3 \mathrm{G}$ and $4 \mathrm{G}$ phones, but many $2 \mathrm{G}$ phones were not available.

Outside of these datasets, no other personally identifiable information was utilized, such as participant names or social media accounts.

4.1.1 Data Collection. Our data was collected over two and a half years in Bokondini (August 2014 to April 2017) and one year in 
San Andres (April 2016 to April 2017). As part of the GSM protocol, a phone attempts to camp on a tower by sending a Location Update Request (LUR) to the tower. This LUR contains both the IMSI and IMEI of the phone attempting to connect. It is from these connection attempts that we gather the quantitative data used in the study.

The GSM protocol also specifies how phones select their towers. A phone first scans the supported frequency bands for towers available. From that list of towers it selects ones that match the provider's SIM card. If none of those are available, it will attempt to connect to whatever other towers are present. Since the towers we observe are the only active towers in the region, this means all phones in the area attempt to camp. As such, our TAC records are comprised of all phones that pass through the coverage area of the two access points and provide a complete, ground truth view into the phones being used in this area.

\subsubsection{Operational Definitions.}

Local vs. Non-local Subscribers. In subsequent analyses we will differentiate between local and non-local users. We define local users as those who either bought a SIM on the community cellular network, or had their SIM active on the local network for at least 10 days. This latter criteria was applied to deal with the fact that San Andres has a significant tourism industry, and we don't want these transient phones to skew our results toward a more urban set of user demographics. ${ }^{1}$

Definition: A local user is one who has a SIM for the local telecom or has had their phone present in the community for at least ten days.

Non-local phones are those who camp on the network but do not meet the above criteria.

Primary Phone. While it's easiest to assume a user doesn't change phones often, prior work has shown that sharing of phones and SIMs is common in much of the developing world [3, 10]. As such, attempting to determine if a user has upgraded their phone could be confusing. To mitigate this concern, we introduce a notion of a primary phone.

Definition: A user's primary phone is the phone their SIM registered to the network with most often during a day.

For example, a participant may use an iPhone $3 \mathrm{G}$ as their primary phone for 2 months, while perhaps letting others install their SIMs in the phone for a few minutes a day.

Phone Upgrade. As one of the main questions we seek to answer with this data is why and how users are upgrading to $4 \mathrm{G}$, we need to define what we consider to be an upgrade. As mentioned above, users often share both SIMs and phones, so we cannot naively count any change in phone as an upgrade. Instead, because of the

\footnotetext{
${ }^{1}$ For example, 4000 IMSIs (out of 10000 total) were present for only one day in the lifetime of the Indonesia network. Similarly, for the Philippines, 70000 IMSIs (out of 100000 total) were present for just one day. To determine which of the population should be considered local to the area, we plotted the number of SIMs active over number of days in the network. The plots are monotonically decreasing and we use the elbow point in the graph of 10 days to filter local users from non-local users. Filtering users with this estimate gives us 968 unique IMSIs in Bokondini and 2600 unique IMSIs in San Andres.
}

longitudinal view we have of the network, we can remove the case where the phone is returned to its original owner.

Definition: A user has upgraded their phone when they change their primary phone to another and do not switch back.

Phone Sharing. Analogous to phone upgrades, we can also quantify the amount of phone sharing in the network. In this case, instead of a user changing from one phone to another, we count how often a phone changes to another user and back. While not directly related to phone upgrade behavior in the network, this statistic will provide a deeper understanding of user behavior in these networks and potentially inform mechanisms for increasing $4 \mathrm{G}$ adoption.

Definition: A phone is shared if it changes users with operation returning to earlier users.

\subsection{Qualitative Interview Design}

To get a better understanding of the $4 \mathrm{G}$ 'mobile phone frenzy' [23] in the Philippines, we conducted semi-structured, topical interviews in San Andres. Unfortunately we could not do the same in Bokondini due to political instability in the area during the study.

Phenomenology is the qualitative research paradigm that informed the conduct of the topical interviews on respondents' experience of using and upgrading their mobile phones. The focus is on collecting descriptions of mobile phone users' lived experience to come up with a composite description and an interpretation of this experience [9]. Because the interviews were one-sitting interviews, the researchers tested for communicative validity in analyzing the empirical material. Thus, the qualitative responses of the interview participants were compared across several demographic criteria, such as age, gender, occupation, and nominal descriptions of level of technological background, to identify the most coherent interpretation that would explain their experiences as a collectivity [28].

\subsection{Data Collection Limitations}

Unfortunately, the data we were able to collect in this study was uneven. For instance, we gathered hourly TAC logs for the Philippines but not for Indonesia. This is because the two networks are separate and we did not set one policy for both. We gathered two and a half years of logs for Indonesia but only one year for the Philippines. This is because the Filipino network was installed later. We conducted interviews in the Philippines and not Indonesia, because of political issues in Bokondini. This lack of symmetric data collection limits the breadth of the study.

\section{RESULTS}

\subsection{Local vs Non-Local Users}

We begin by analyzing the differences in phone types for local and non-local users in both communities. As can be seen in Figure 4, local and non-local users in Indonesia are quite similar in their total use of feature phones vs. smartphones: local phones were $60.0 \%$ $2 \mathrm{G}$ and $11.2 \% 4 \mathrm{G}$; non-local phones were $58.8 \% 2 \mathrm{G}$ and $15.2 \%$ were 4G. By contrast, differences between local and non-local devices in the Philippines were pronounced. There, $51 \%$ of local phones are $2 \mathrm{G}$ while $15.9 \%$ were $4 \mathrm{G}$; for non-local phones, only $27.4 \%$ were $2 \mathrm{G}$ 

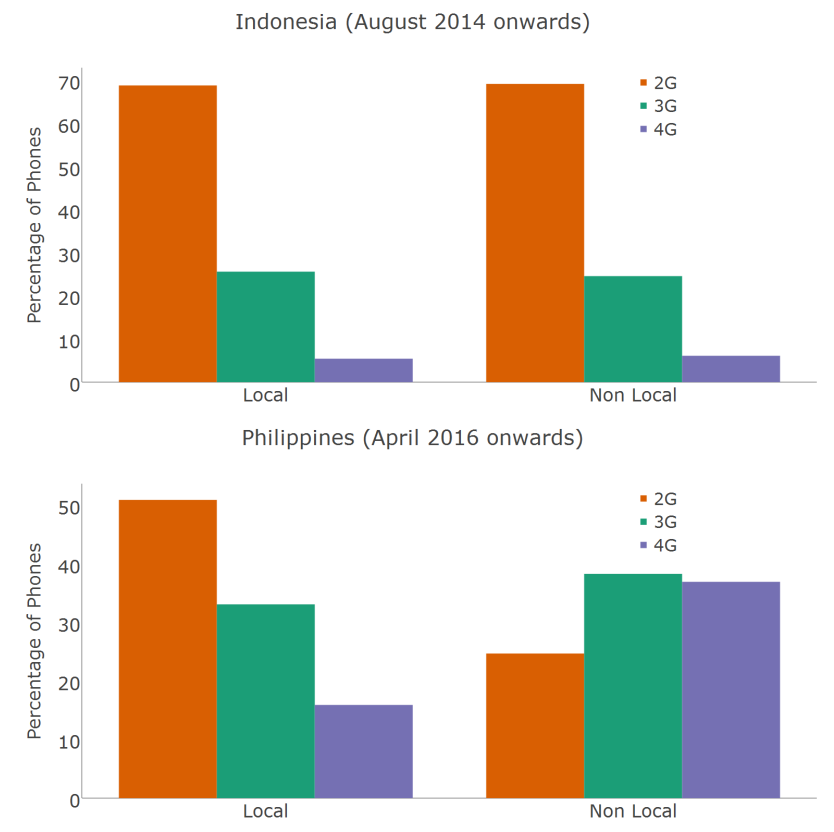

Figure 4: Local and non-local phones in use in past year in Indonesia (top) and Philippines (bottom). There is little difference for local and nonlocal in Indonesia, but a large difference for Philippines.

while $37 \%$ were $4 \mathrm{G}$. For this reason, unless stated otherwise, the analyses that follow focus on local subscribers of both networks.

\subsection{Phone Adoption}

We next analyze trends in smartphone adoption over time in the two rural networks. The results are shown in Figure 5. In Bokondini, where we have nearly three years of data, the changes are dramatic. Between August 2014 and April 2017, 4G adoption increased from $0.2 \%$ to $17.9 \%$ (a $90 \mathrm{x}$ increase) in the last month. In the last year alone, adoption rose from $6.5 \%$ to $17.9 \%$, a growth of nearly $2.75 \mathrm{x}$. This was primarily done at the expense of feature phones, as the $3 \mathrm{G}$ adoption rate remained relatively unchanged throughout the entire trial period (22.5\% in October 2014 to $25.9 \%$ in April 2017). Feature phone (2G) adoption dropped from $77.3 \%$ to $56.3 \%$ over the same period of time.

For San Andres, the growth in $4 \mathrm{G}$ adoption was strong, though not as pronounced as in Indonesia. In the year of data we observe, adoption rose from $11.8 \%$ in April 2016 to $22.5 \%$ in April 2017 (2x year over year). $3 \mathrm{G}$ adoption again remained constant, with $35.3 \%$ adoption in 2016 to $33.6 \%$ in 2017. $2 \mathrm{G}$ feature phone dropped from $53 \%$ to $43.9 \%$, and is no longer a majority of the total phones in the area.

\subsection{Projecting Viability}

The above results tell a compelling story about technology shift in rural areas. $4 \mathrm{G}$ smartphone adoption is growing rapidly in both networks despite the lack of general Internet connectivity. Operators
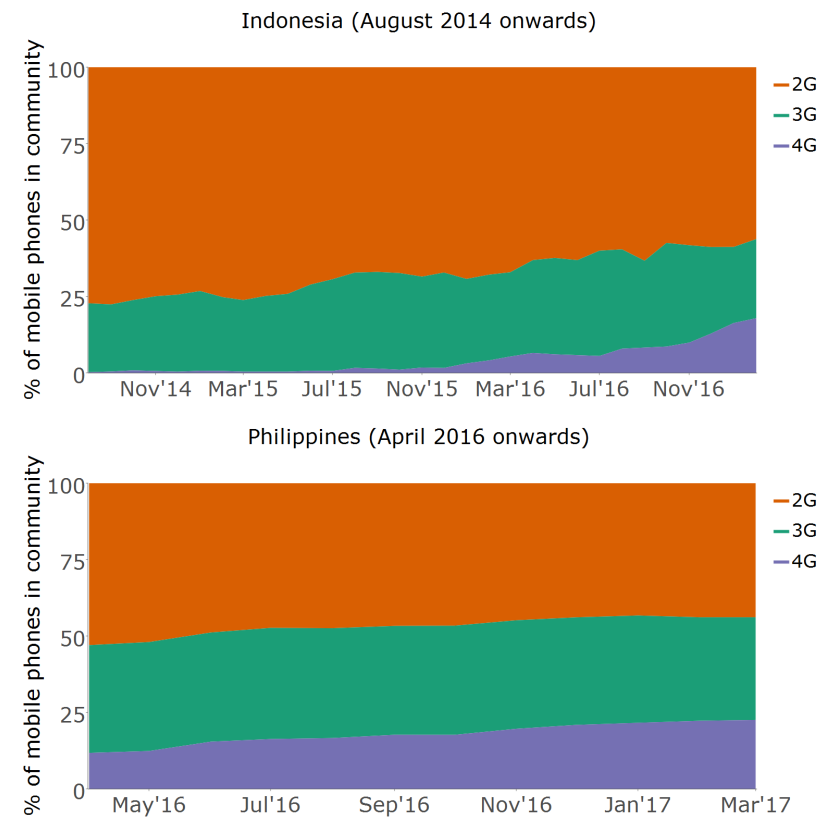

Figure 5: Distribution of local phone types over time in Indonesia (top) and Philippines (bottom). 2G phones are red, $3 \mathrm{G}$ green and $4 \mathrm{G}$ blue. $3 \mathrm{G}$ growth has stagnated and stopped in both communities while $4 \mathrm{G}$ has grown significantly.

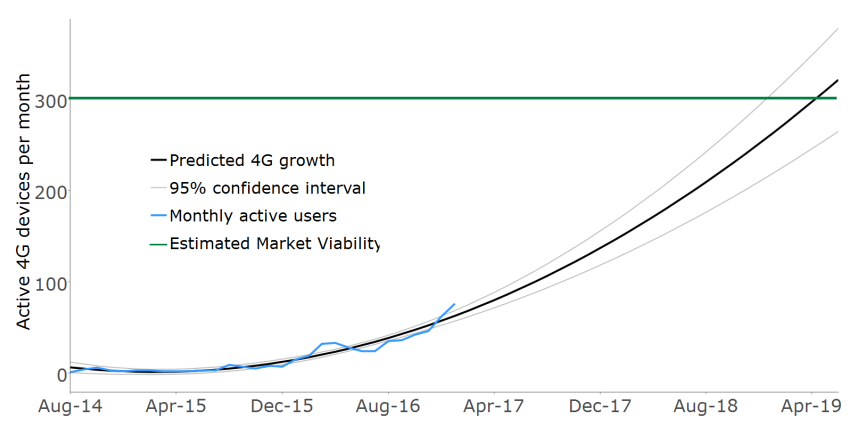

Figure 6: Projected local 4G growth in Indonesia

may soon be able to leverage this trend to install 4G-only basestations even in these most remote areas. Moreover, these upgrades are seemingly skipping $3 \mathrm{G}$, with users replacing their $2 \mathrm{G}$ feature phones with more modern $4 \mathrm{G}$ smartphones.

In Figure 6, we show the projected growth of $4 \mathrm{G}$ adoption in Bokondini from now until 2019, based on a model fit on the data collected between 2014 and 2017. Specifically, we fit a quadratic regression of number of monthly users $Y_{t}$ on time $t$, as $Y_{t}=\alpha+$ $\beta_{1} t+\beta_{2} t^{2}+\epsilon_{t}$. We show only Indonesia because the relatively short period of data collection in the Philippines (1 year) is insufficient for robust projections.

Bokondini had roughly 100 active $4 \mathrm{G}$ phones in the area as of April 2017, and the projections indicate that there will 200 active phones by August 2018, and 300 active 4G phones by March 2019. From informal discussions with the local carrier, they estimate that 
Table 2: Local Phone Upgrades

\begin{tabular}{lccc}
\hline From: & To: Feature phone & To: $3 \mathrm{G}$ & To: $4 \mathrm{G}$ \\
\hline Panel A: Philippines & & & \\
Feature phone & $39.75 \%$ & $3.56 \%$ & $13.79 \%$ \\
3G & $4.70 \%$ & $3.58 \%$ & $3.18 \%$ \\
$4 \mathrm{G}$ & $12.38 \%$ & $3.66 \%$ & $15.51 \%$ \\
\hline Panel B: Indonesia & & & \\
Feature & $55.38 \%$ & $1.32 \%$ & $13.26 \%$ \\
3G & $1.60 \%$ & $1.65 \%$ & $0.85 \%$ \\
$4 \mathrm{G}$ & $14.73 \%$ & $0.94 \%$ & $10.25 \%$ \\
\hline
\end{tabular}

this target of $3004 \mathrm{G}$ phones present in the addressable market is the break-even level at which point it is financially sustainable to deploy $4 \mathrm{G}$ technology. ${ }^{2}$ Assuming that people with $4 \mathrm{G}$ phones would use data services at an ARPU similar to the existing $2 \mathrm{G}$ services (which remains to be seen), these back-of-the-envelope projections indicate that the network would likely be financially viable in early 2019 .

\subsection{Phone Upgrades}

As discussed in Section 4.1.2, we define a phone upgrade as when a user moves from one primary phone to another without reverting to their original device. Table 2 shows the upgrade matrix for both San Andres and Bokondini, where a row represents the old device and the column represents the new device. For instance, 39.75\% of all upgrades in the Philippines are from one feature phone to another. The results broadly support the phone adoption rate seen in the prior section; users are skipping $3 \mathrm{G}$ entirely and only moving between $2 \mathrm{G}$ feature phones and $4 \mathrm{G}$ smartphones. Since the starting population of $2 \mathrm{G}$ phones is already very high, the $14 \%$ of feature phone upgrades going to $4 \mathrm{G}$ represents a significant fraction of the entire network.

It is also worth noting that it appears there was nearly equivalent amounts of phone downgrading as upgrading for $4 \mathrm{G}$ users. This is not something we expected, and to our knowledge has not been previously documented. This downgrading behavior may indicate that users are shifting to $2 \mathrm{G}$ phones due to the lack of a $4 \mathrm{G}$ network. That implies there may be latent $4 \mathrm{G}$ demand that could manifest if the network were upgraded. It also suggests that $4 \mathrm{G}$ phones are not appropriate for these rural areas; in our interviews we discover that they consume too much power and are too fragile to survive in difficult conditions (see Section 5.8).

\subsection{Upgrade Age}

We also investigate the age of phones being upgraded. For this, we use the TAC data (Section 4.1) to query an Internet database that tells us, for most phones, the manufacture date of the phone. This is compared against the time the upgraded phone was first present on the network. As can be seen using Table 3 and Table 4, the San Andres appears to have a much more robust secondary market than Bokondini (perhaps due to the proximity to a major urban area),

\footnotetext{
${ }^{2}$ Specifically, they report the need for 120 active subscribers, with roughly $40 \%$ pene tration into the local subscriber base. This means that we wish to know when there will be 300 total $4 \mathrm{G}$ phones local to the Indonesia network.
}

Table 3: Age-Statistics of "New" Phones in Philippines

\begin{tabular}{lcccc}
\hline & Mean & Median & Std. Dev & Num. Phones \\
\hline 2G to 3G & 2.53 years & 2 years & 2.11 years & 267 \\
2G to 4G & 1.89 years & 2 years & 1.16 years & 93 \\
3G to 4G & 1.65 years & 2 years & 1.19 years & 87 \\
4G to 4G & 1.38 years & 1 year & 1.05 years & 75 \\
\hline
\end{tabular}

Table 4: Age-Statistics of "New" Phones in Indonesia

\begin{tabular}{lcccc}
\hline & Mean & Median & Std. Dev & Num. Phones \\
\hline 2G to 3G & 2.73 years & 2 years & 1.67 years & 67 \\
2G to 4G & 0.66 years & 1 year & 0.49 years & 12 \\
3G to 4G & 0.85 years & 1 year & 0.39 years & 17 \\
4G to 4G & 0.75 years & 1 year & 0.58 years & 28 \\
\hline
\end{tabular}

with users upgrading to phones that are, on average, over a year old. In Indonesia, users are instead upgrading to more modern phones that were produced within the last year. In Indonesia, there is no clear difference between the upgrade ages given the user's previous device; a $2 \mathrm{G}$ phone holder may upgrade to a more recent device than a $3 G$ phone holder. In the Philippines, users of a $4 \mathrm{G}$ phone are more likely to upgrade to a recently manufactured phone than $2 \mathrm{G}$ or $3 G$ users. This may be a wealth effect, or just a measure of the upgrade cycles present in the Philippine secondary market.

\subsection{Phone Sharing}

Phone sharing is a common practice in many developing countries [5, 6, 21], and in many ways is a counterpoint to phone upgrading. While we cannot distinguish between two individuals who share the same device and SIM card, we can detect when a single device (IMEI) is used by multiple SIMs. Figure 7 shows, for each type of device, the fraction of those devices that are used by more than one SIM. On running a parametric t-test, we observe that $2 \mathrm{G}$ phones are shared significantly more than $3 \mathrm{G}$ and $4 \mathrm{G}$ phones in both the communities ( $\mathrm{p}<10^{-16}$ in both cases).

The fact that feature phones are more frequently shared than smartphones is potentially counterintuitive; as a scarcer commodity, it would likely be in higher demand, and in some cases people might pool resources in order to upgrade. On the other hand, it could be that smartphones are more expensive, more fragile, have shorter battery lives, or other factors that might discourage sharing. Here, our qualitative interviews provide some insight: many subjects had negative experiences with losing or damaging their primary phones, often from sharing. Another factor that participants cited was the relative ease of sharing $2 \mathrm{G}$ phones: they are simple to use, quick to set up, and utilize less unique information about the user.

\subsection{Phone Activity}

Our final set of quantitative results explore differences in the extent to which feature phones and smartphones are active on the San Andres network. Figure 8 shows, by device type, the average number of hours per day for which the device is active on the network, 
Indonesia

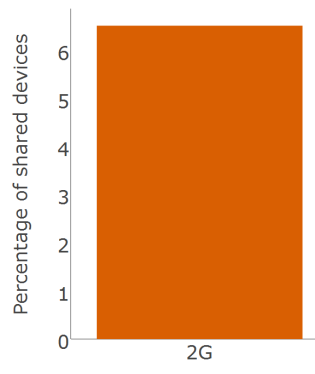

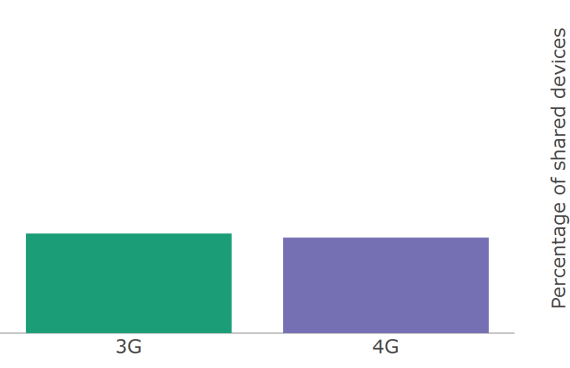

Figure 7: The local phone sharing ratio in Indonesia (left) and the Philippines (right). Features phones are red, $3 G$ green and $4 \mathrm{G}$ blue. $2 \mathrm{G}$ phones are shared much more than $3 \mathrm{G}$ or $4 \mathrm{G}$ phones.

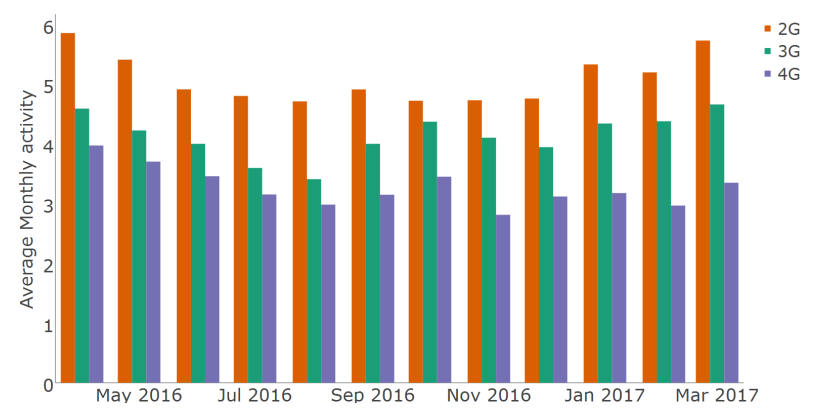

Figure 8: Hours of local Filipino network activity over time. $2 \mathrm{G}$ phones are significantly more active than smartphones.

as constructed from the hourly TAC logs. ${ }^{3}$ The results show that users with $2 \mathrm{G}$ phones keep them active more than users with $3 \mathrm{G}$ phones, who again are more active than users with $4 \mathrm{G}$ phones. This is again somewhat counterintuitive; if you have a $4 \mathrm{G}$ phone for media purposes, wouldn't you use it more? One likely hypothesis for keeping your $4 \mathrm{G}$ phone inactive is due to the lack of community power infrastructure in the area. Despite the better media playing properties of smartphones, they need to be turned off to conserve power in areas where you aren't leveraging the other $4 \mathrm{G}$ capabilities of the phone. Secondly, $2 \mathrm{G}$ phones are simply more efficient in idle mode; some generic $2 \mathrm{G}$ feature phones can operate with over three days of standby time, significantly more than a power-hungry smartphone.

\subsection{Philippines Interviews}

The prior figures and tables highlight several prominent trends and regularities of phone use in two rural communities. To provide more nuance and depth to these results, and in particular to develop a better understanding of the role of smartphones in communities

\footnotetext{
${ }^{3}$ This registration implies that the user's phone was active during that hour. As such, a phone that sends more registrations in a day was actively powered-on more than one that did not. There are some caveats; phones in airplane mode will not attempt to register and a phone that is on for one minute will be counted as often as a phone that was powered on for fifty-nine minutes. Unfortunately, we gathered only daily TAC logs in Bokondini and do not have the granularity to measure phone usage per day for that network, as we only know if a phone was active at all that day and not their amounts of activity relative to other phones.
}

without Internet connectivity, we conducted interviews in San Andres, following the protocol described in Section 4.2.

We were able to interview two of the five SIM card dealers in San Andres; the other three SIM card dealers were not available. In separate interviews, we asked the dealers to give us a general description of their clients (buyers of SIM cards and/or pre-paid airtime). We also asked them about their general observation about their clients' cellphones. The two SIM card dealers note that most of their clients are young people and that younger people in the area own "touchscreen phones" (i.e., smartphones) while the older ones own "keypad phones" (i.e., feature phones). This information became the basis for initiating the 'snowball' technique in identifying respondents. We positioned ourselves in public places in the Barangay and approached young adults for interviews. After each interview, the researcher asked the respondent to refer additional respondents in the Barangay including possible respondents who are no longer young adults. In total, we conducted 15 topical interviews with individual users, in addition to the two interviews with SIM card dealers. All interviews were conducted in San Andres in Tagalog by native speakers.

The age range of interview participants is from 18 to 67 years of age, where nine (9) are within the age range of 18 to 30 or young adults and six (6) are older than 30 years old. Ten of the fifteen participants are female. Respondents' primary occupation is as homemaker (5), otherwise employed (4), students (3), unemployed (2), and retired (1). The researchers classified the interview participants according to the latter's mobile phones during the interview as follows: $2 \mathrm{G}=4$ participants, $3 \mathrm{G}=4$ participants, $4 \mathrm{G}=7$ participants.

All of the interview participants reported that their exposure to ICTs is mainly through the use of mobile phones. All of them are aware that there are mobile phones that can do much more than facilitate communication, although young adults are better able to describe the other capabilities of their mobile device) [27]. Interview respondents do not refer to their mobile phones as $2 \mathrm{G}, 3 \mathrm{G}$, or $4 \mathrm{G}$, but young adults are aware that $3 \mathrm{G}$ and $4 \mathrm{G}$ phones are more powerful than $2 \mathrm{G}$. Interview respondents classify phones by describing the phone's capabilities, thus phones are either touchscreen or keypad and Internet-capable or not. As a 22-year old female respondent who owns a $4 \mathrm{G}$ mobile phone describes it: 
Respondent 7:"If you have a touchscreen phone, you can do many things with it. You can access the internet. Unlike before, you can only do calls and text. But now, (with a touchscreen phone), you can call, text, (connect to the) internet, and other things."

Except for two (the two oldest), almost all interview participants have upgraded their phone models because of their desire for a more powerful phone. Those two older interview participants have actually downgraded their phone type from a smartphone to a feature phone because they found feature phones more durable and sufficient for their needs (e.g. calls and text messaging).

General observations. Interview participants use their phones as communication devices. The nature of their communication is predominantly personal, involving family members, friends, and loved ones, especially those who live and/or work outside of San Andres. Almost all of the interview participants have a Facebook (Facebook Lite) account to maintain existing kinship ties, to reestablish old personal ties, and to build new ties. Communication may also involve employers or business associates.

During the interviews, verbal and non-verbal cues indicate that young adults seem dissatisfied and unimpressed with the local community cellular network because it could only provide call and text messaging services. While the Philippines is commonly referred to as "the texting capital of the world" [24] we find that in the remote rural Barangay of San Andres, people with $4 \mathrm{G}$ phones minimize texting and voice calls because it is more expensive when compared to traveling to nearby town centers to access free WiFi services for the public. They prefer to use instant messaging platforms such as Facebook Messenger, Snapchat, and WhatsApp in these places because communication is real-time. Two participants preferred to be interviewed together and their joint account was quite descriptive:

Respondent 3: "We still don't have internet here." Respondent 4: "Sometimes, (we get cellular signal) in the mountains. We go there to send a text message to our boyfriends.

Respondent 3:"Then, you can't be sure if the message was sent..."

Respondent 4:"We don't send text messages anymore. We send PMs through Facebook Lite, Viber, WhatsApp...

Respondent 3:"Now, you can see if they are online. You know immediately if they are replying. Unlike before when you need to wait..."

Respondent 4:"You will wait like waiting for a telegram..."

Thus, while San Andres does not have 4G connectivity, participants report traveling to places outside of the community with free WiFi to make use of data. In a sense, they are able to transgress the limitations of their physical and social context by traveling to areas where the services they require are more accessible. The structure of the telecommunications market facilitates this process: consumers in the Philippines commonly own multiple SIM cards from multiple operators, and frequently switch to the SIM card that is most relevant and affordable to the local market in which they inhabit. This helps explain the dominance of $2 \mathrm{G}$ phones in our quantitative work: many individuals report using feature phones

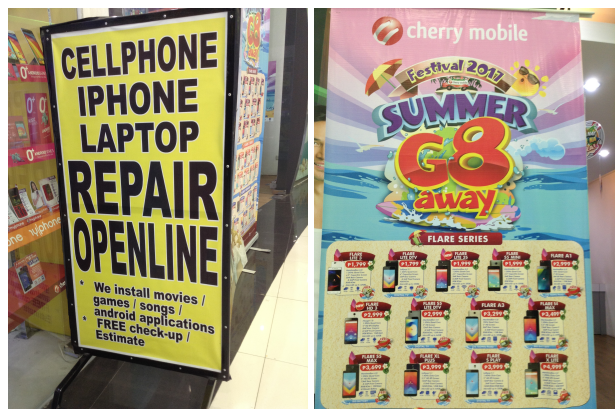

Figure 9: Examples of Filipino advertisements, with media downloads (left) and youth targeting (right).

within San Andres, but then switching to a smartphone when outside of the Barangay. This behavior, if anything, would lead us to underestimate the demand for $4 \mathrm{G}$ services, as seen in Section 5.3.

Entertainment. Inside the Barangay (and outside of Internet connectivity), phones are commonly used as a cheaper entertainment device. In addition to the camera - which was one of the most important functions to many participants - commonly reported uses include listening to music, watching movies, and watching television shows (especially local, Korean, and Japanese shows). Through their network of friends outside of San Andres or by occasionally getting connected to the Internet, they are able to store and share entertainment files that could be re-shared or enjoyed together with family and friends in San Andres, where they have very limited entertainment options. Apps that are used for these activities include Share.It and Youtube. Cellphones are also commonly used as a gaming device. Games, like music and videos, are copied or downloaded onto their cellphones. This is particularly true for those who are less mobile, who place a high premium on phones with better audio/video, faster performance, and that facilitate sharing of content. As a 25 year-old tricycle driver who has a $3 \mathrm{G}$ phone narrates:

Respondent 12:"This cellphone belongs to my wife, but my child uses it. My child is seven years old. We use it just for games, music, Facebook. (Facebook) is the only (app) that we know (how to use) here. I let him download as many games as possible, then I will borrow the phone from him.

It is worth noting the emergence of social networks of entertainment enthusiasts that facilitate file-sharing. In pursuing this analytical lead, we did a quick ocular visit and initial content analysis of materials in nearby commercial centers. These revealed that cellphone dealers and repair shops in malls have matched this userdefined desire with commercial services such as downloading of entertainment files for a fee (see Figure 9). It is equally interesting to note that according to respondents, families share entertainment files that are stored in the mobile phone of a family member. They say that this is a more affordable alternative compared to going to the movies or to subscribing to cable television as sources of family entertainment. 
Upgrades and downgrades. To contextualize the upgrade behavior that was a focus of earlier sections, we asked participants about their reasons for changing phones. Women respondents say that they would have to immediately replace their cellphones when these are lost, stolen, or permanently damaged because mobile phones are necessary for them to keep in touch with their loved ones especially those who live and work outside the Barangay. For most respondents, regardless of gender or occupation, upgrades are justified when their mobile phone is prone to stalling or hanging or has a limited storage capacity because then the phone's entertainment function is hampered. Unplanned upgrades were also frequently reported, where lower end (but still functional) phones are gifted to loved ones, for instance to a younger sibling, a relative, or even to an elder adult.

In determining what device to upgrade to, affordability is critical. Higher end cellphones from cheaper brands proliferate in San Andres. These units are bought either as brand new phones or second-hand (used). Aside from cost, phones are deemed better or worse in terms of functionality: faster, bigger storage capacity, wider screen, better camera, and better video graphics. Aesthetics also matter, and slimmer models are considered more stylish.

\section{DISCUSSION}

The smartphone frenzy in remote and isolated villages may seem irrational, given that these communities do not have $4 \mathrm{G}$ network infrastructure in place. Yet our quantitative and qualitative analysis shows that smartphone use is quite prevalent and provides some insights to explain this phenomenon. Here, we summarize a few of these key insights, and discuss how they can inform the broader discussion around connectivity in developing regions.

\subsection{Supporting 4G Adoption}

Infrastructure Support. One key finding of this work is that while there is still robust uptake of $2 \mathrm{G}$ phones, the market for $3 \mathrm{G}$-only phones is dying. This means that any attempt to increase smartphone adoption will involve increasing adoption of phones that support $4 \mathrm{G}$. While operators may still wish to deploy $3 \mathrm{G}$ networks for other reasons (e.g., patent encumbrances on $4 \mathrm{G}$ or extra hardware in a warehouse) there will be no reason to do so based on adoption in the near future. Indeed, we note the phone downgrading results from Section 5.4 that show that $4 \mathrm{G}$ users in our network switch back to $2 \mathrm{G}$ phones as much as they upgrade to $4 \mathrm{G}$ phones. This implies that these users entered the rural area with a $4 \mathrm{G}$ phone and decided to switch back during their time in our networks.

It seems likely that if there were $4 \mathrm{G}$ coverage available in the community these users would be incentivized to stick with their existing $4 \mathrm{~g}$ phone. The capabilities lost in the step down to a $2 \mathrm{G}$ network would mitigate many of the advantages of the device. Similarly, during our interviews users noted that power was a primary limitation on their use of smartphones. This is supported by our measurements in Section 5.7, where we found that $4 \mathrm{G}$ phones were less active on the network (in terms of registrations) than $2 \mathrm{G}$ or $3 \mathrm{G}$ phones. As such, the data (both TAC logs and interviews) seem to imply that better infrastructure (both network and power) in a community would increase $4 \mathrm{G}$ adoption. Solutions like microgrids [22] or joint $2 \mathrm{G} / 4 \mathrm{G}$ basestations may be what is needed. Unfortunately, these rural areas, by their nature of being rural and low-income, lack exactly this kind of infrastructure.

Driving Entertainment. One primary finding from the interviews was the importance of entertainment as a driver of $4 \mathrm{G} /$ smartphone adoption. Over half of the interviewees noted an entertainment function (music, games, or video) as one of the primary uses for their phone and a reason for upgrading to a newer device. Users used their phones to download, copy, store, and play audio and video files for both their own personal use as well as for community or family use. For example, one of the interview subjects, a 22-year old construction worker in San Andres, watches video and listens to music from a memory card, which he loads with content from outside of the community. Even in an area without cellular coverage, users batch store this content on their smartphones for distribution.

There may be an opportunity to encourage $4 \mathrm{G}$ phone adoption by providing media that can most efficiently be shown on $4 \mathrm{G}$ smartphones. Examples such as a Youtube Accelerator [13] allow local caching of audio or video content and could provide support for locals to buy a $4 \mathrm{G}$ phone to use in the community.

"Hardening” Devices. The primary reason for switching phones given in the interview was loss of the device; theft or destruction. For example, the 22-year old construction worker discussed above had upgraded from a feature phone to a cherry mobile (a local smartphone) phone. He then upgraded to a nicer smartphone after dropping the cherry mobile phone in some water. Another way to encourage $4 \mathrm{G}$ adoption would be to harden smartphones against these types of loss. Some feature phones are notoriously resilient and having smartphones with the same ruggedness would be better-suited to the conditions of harsh rural environments where power and weather often destroy hardware [31]. Similarly, it may be that allowing for repair is the answer. Prior work has explored the incredible depth of phone repair in developing regions [20]. Unfortunately, the social infrastructure and knowledge required for repair is often unavailable in rural areas.

Theft is a trickier problem. For instance, a 28-year old female homemaker in San Andres was forced to downgrade from a Samsung Galaxy to a Cherry Mobile phone when the Samsung was loaned to a friend of her child and not returned. As part of a community network, it is possible we could provide stronger tooling for detecting and thwarting theft of devices within our network. Major telecoms have, in the past, provided a blacklist service for blocking stolen IMEIs, but that feature is not well supported. Implementing a similar service within the community network could discourage phone theft, but if the phone left our community we could no longer enforce any theft policy.

Policy Rationale. There are many benefits of moving rural users to $4 \mathrm{G}$ handsets. Users gain access to a more feature-rich device that can access both traditional telephony as well as Internet services. This device can help them engage with increasingly online government and financial services. Lastly, as the interviews clearly noted, the smartphone is a much better device for consuming entertainment. Similarly, it would be largely beneficial to operators and regulators if the users transitioned to $4 \mathrm{G}$. Refarming of $2 \mathrm{G}$ spectrum would create more bandwidth as well as allow for a sunsetting of legacy $2 \mathrm{G}$ cellular infrastructure, which is extremely expensive. 
One key thing about phone upgrades is that, from a user perspective, each network technology is a superset of all prior technologies. This means that every $3 \mathrm{G}$ phone supports both $2 \mathrm{G}$ and $3 \mathrm{G}$ and every $4 \mathrm{G}$ phone supports $2 \mathrm{G}, 3 \mathrm{G}$, and $4 \mathrm{G}$. This means that $2 \mathrm{G}$ basestations will continue to be relevant even as $4 \mathrm{G}$ phones become the dominant paradigm. There is an option for operators to install dual $2 \mathrm{G} / 4 \mathrm{G}$ basestations. While not a common model yet (due to the fact that $2 \mathrm{G}$ networks often already exist) these would be a great mechanism for encouraging $4 \mathrm{G}$ adoption while supporting the current install base.

Of course, the big limiter on existing operator $4 \mathrm{G}$ rollouts is the lack of backhaul in rural areas. $2 \mathrm{G}$ access points can be serviced by a (relatively) small satellite terminal (as they are in both of our community networks). A 4G base station usually requires a fiber connection, which is extremely expensive, and therefore rare, in rural areas. This means it may be the case that user adoption of $4 \mathrm{G}$ phones will outpace roll-outs of $4 \mathrm{G}$ networks.

Possible Downsides of $4 G$. While we believe the shift to ubiquitous $4 \mathrm{G}$ networks and mobile phones to be a net positive, there are negative elements to the shift away from $2 \mathrm{G}$. In particular, as mentioned above, smartphones are power hungry and fragile. Also, while they are getting cheaper, they are still more expensive than a similar-year $2 \mathrm{G}$ phone. Despite potential solutions to these problems, having 4G-only basestations would require users to buy devices that may not fit their environment. It is our hope that, as $4 \mathrm{G}$ networks become ubiquitous, extremely low-end $4 \mathrm{G}$ phones will start to be manufactured. These may even have the affordances of a traditional feature phone.

Future Networks. Though our focus is on LTE, technology companies are continuing to develop new wireless protocols that will eventually be present on future phones. It's reasonable to ask if and when the next generation $(5 \mathrm{G})$ networks will be relevant in rural areas. As the first prototype LTE networks went live in nearly a decade ago in 2009 and the first $5 \mathrm{G}$ networks are just now being deployed, one might expect a similar wait for their wide-area adoption. As for now, there's plenty of room for growth in LTE.

\subsection{Contextualizing Connectivity}

The trends we observe become more intelligible if we look beyond the the lens of personal choice or preference. Weaving the broader social context into the interpretation of individual accounts, one is able to render visible other powerful forces that are driving $4 \mathrm{G}$ growth. For instance, the dominant marketing strategy of cellphone manufacturers and telecoms is important. Even a cursory look at advertisements and other promotional materials (see Figure 9) in selling $4 \mathrm{G}$ phones reveal a marketing strategy that is mainly focused on consumerist constructions of a "youth lifestyle", which is similar to what was earlier suggested by Carroll et al. [7]. While we might expect that sophisticated gadgets would target "higherend" consumers, in practice the marketing strategy deliberately focuses on lower-end markets, even users in remote, rural villages.

Therefore, we are observing a systematic and rapid integration of remote rural villages into the global market and within the framework of a global consumerist culture through ICTs. Yet, all of the potential benefits from ICT adoption do not automatically accrue to upgraders because of the absence of necessary physical and social infrastructure that would enable them to use their cellphones beyond personal communication and personal entertainment.

Where, then, is there room for change? In this study, we found it in the noticeable practices of small acts of transgression, or what James C. Scott referred to as 'weapons of the weak' [29], to circumvent context by cellphone users in a remote rural village. As previously mentioned, cellphone users change SIMs or travel to other places to take advantage of free wifi and avoid the costs of texting and voice calls. This lived experience apparently leads to feelings of dissatisfaction with poor (inaccessible and expensive) connectivity services, and therefore experience with mobile phone use raises technological consciousness even if users have a low level of technological consciousness via other gadgets to begin with.

\subsection{Study Limitations}

Generalizability. This study is a qualitative and quantitative analysis of phone upgrades in two specific rural community cellular networks. These networks have a number of unique properties that imply that the results may not generalize. The first is that these are community cellular networks. Phone adoption in more traditional incumbent networks may be different. Those networks will likely support data service and better integrate with the rest of the country-wide system. Second, these networks sit in certain rural areas with their own unique properties. Though the results have generalized across two very different communities in different countries, there are likely to be changes in other communities.

\section{CONCLUSION}

We are in the midst of a massive shift from $2 \mathrm{G}$ cellular networks to modern IP-based $4 \mathrm{G}$ networks. Caught in this shift are rural areas that are currently uncovered or undercovered. In these communities, operators are currently deploying aging $2 \mathrm{G}$ technologies as there are not enough potential customers with devices that support $4 \mathrm{G}$ connections. At the same time, users are discouraged from upgrading as their local network does not support the many affordances of their $4 \mathrm{G}$ phones.

This work explored mobile phone upgrade behavior in two remote communities in the Philippines and Indonesia. We utilized TAC logs to provide a detailed record of all cellular phones in these two regions. We also conducted fifteen semi-structured interviews in the Philippines to get a deeper understanding of user behavior. From these analyses we discovered that $4 \mathrm{G}$ phones are common despite the lack of $4 \mathrm{G}$ coverage, $4 \mathrm{G}$ adoption is accelerating, users are skipping $3 \mathrm{G}, 2 \mathrm{G}$ phones are more active and shared, and that media was a primary driver of smartphone adoption. We conclude by suggesting that telecoms consider ignoring $3 \mathrm{G}$ rollouts and provide several potential mechanisms for accelerating $4 \mathrm{G}$ adoption in these rural areas.

\section{ACKNOWLEDGEMENTS}

We wish to thank Jenn Webster for assistance in writing.This work was funded by Facebook and a grant from the Financial Services for the Poor program at the Bill and Melinda Gates Foundation. 


\section{REFERENCES}

[1] Sohaib Ahmad, Abdul Lateef Haamid, Zafar Ayyub Qazi, Zhenyu Zhou, Theophilus Benson, and Ihsan Ayyub Qazi. 2016. A View from the Other Side: Understanding Mobile Phone Characteristics in the Developing World. In Proceedings of the 2016 Internet Measurement Conference (IMC '16). ACM, New York, NY, USA, 319-325. https://doi.org/10.1145/2987443.2987470

[2] Joshua Blumenstock, Gabriel Cadamuro, and Robert On. 2015. Predicting poverty and wealth from mobile phone metadata. Science 350, 6264 (27 Nov. 2015), 10731076. https://doi.org/10.1126/science.aac4420

[3] Joshua Blumenstock and Nathan Eagle. 2010. Mobile Divides: Gender, Socioeconomic Status, and Mobile Phone Use in Rwanda. In Proceedings of the 4th ACM/IEEE International Conference on Information and Communication Technologies and Development (ICTD '10). ACM, New York, NY, USA, Article 6, 10 pages. https://doi.org/10.1145/2369220.2369225

[4] Joshua E. Blumenstock, Michael Callen, Tarek Ghani, and Lucas Koepke. 2015 Promises and Pitfalls of Mobile Money in Afghanistan: Evidence from a Ran domized Control Trial. In Proceedings of the Seventh International Conference on Information and Communication Technologies and Development (ICTD '15). ACM New York, NY, USA, Article 15, 10 pages. https://doi.org/10.1145/2737856.2738031

[5] Joshua E Blumenstock and Nathan Eagle. 2012. Divided We Call: Disparities in Access and Use of Mobile Phones in Rwanda. Information Technology and International Development 8, 2 (2012), 1-16.

[6] Jenna Burrell. 2010. Evaluating Shared Access: social equality and the circulation of mobile phones in rural Uganda. Fournal of Computer-Mediated Communication 15,2 (2010), 230-250.

[7] Jennie Carroll, Steve Howard, Jane Peck, and John Murphy. 2002. A field study of perceptions and use of mobile telephones by 16 to 22 year olds. FITTA : fournal of Information Technology Theory and Application 4 (2002), 49-61. Issue 2.

[8] International Data Corporation. 2016. Asia/Pacific Quarterly Mobile Phone Tracker. http://www.gsma.com/globalmobiletrends/. (2016). Accessed: 2017-057.

[9] John W. Creswell, William E. Hanson, Vicki L. Clark Plano, and Alejandro Morales 2007. Qualitative research designs: Selection and implementation. Counseling Psychologist 35, 2 (3 2007), 236-264. https://doi.org/10.1177/0011000006287390

[10] J. Donner. 2015. After Access: Inclusion, Development, and a More Mobile Internet MIT Press. https://books.google.com/books?id=BAlkrgEACAAJ

[11] Facebook. 2017. CommunityCellularManager. https://github.com/ facebookincubator/CommunityCellularManager. (2017). Accessed: 201705-7.

[12] Vanessa Frias-Martinez, Jesus Virseda, and Enrique Frias-Martinez. 2012. SocioEconomic Levels and Human Mobility. Fourhnal of Information Technology for Development (Feb. 2012), 1-16.

[13] Google. 2017. Youtube Accelerator. https://accelerator.withgoogle.com/. (2017) Accessed: 2017-05-7.

[14] GSMA. 2016. Global Mobile Trends. http://www.gsma.com/globalmobiletrends/. (2016). Accessed: 2017-05-7.

[15] GSMArena. 2017. GSMArena. http://www.gsmarena.com/. (2017). Accessed: 2017-05-7.

[16] Kurtis Heimerl and Eric Brewer. 2010. The Village Base Station. In Proceedings of the 4th ACM Workshop on Networked Systems for Developing Regions (NSDR '10). ACM, New York, NY, USA, Article 14, 2 pages. https://doi.org/10.1145/1836001. 1836015

[17] Kurtis Heimerl, Shaddi Hasan, Kashif Ali, Eric Brewer, and Tapan Parikh. 2013. Local, Sustainable, Small-scale Cellular Networks. In Proceedings of the Sixth International Conference on Information and Communication Technologies and Development: Full Papers - Volume 1 (ICTD '13). ACM, New York, NY, USA, 2-12. https://doi.org/10.1145/2516604.2516616

[18] Kurtis Heimerl, Anuvind Menon, Shaddi Hasan, Kashif Ali, Eric Brewer, and Tapan Parikh. 2015. Analysis of Smartphone Adoption and Usage in a Rural Community Cellular Network. In Proceedings of the Seventh International Conference on Information and Communication Technologies and Development (ICTD '15). ACM, New York, NY, USA, Article 40, 4 pages. https://doi.org/10.1145/2737856.2737880

[19] GSMA Intelligence. 2014. Country Overview: Philippines Growth Through Innovation. https://www.gsmaintelligence.com/research/?file=141201-philippines. pdf. (2014). Accessed: 2017-05-7.

[20] Steven J. Jackson, Alex Pompe, and Gabriel Krieshok. 2012. Repair worlds: maintenance, repair, and ICT for development in rural Namibia. In CSCW.

[21] Jeffrey James and Mila Versteeg. 2007. Mobile phones in Africa: how much do we really know? Social Indicators Research 84, 1 (Oct. 2007), 117. https: //doi.org/10.1007/s11205-006-9079-x

[22] P. Achintya Madduri, Jason Poon, Javier Rosa, Matthew Podolsky, Eric Brewer and Seth Sanders. 2014. A Scalable DC Microgrid Architecture for Rural Electrification in Emerging Regions.

[23] BBC News. 2000. Mobile phone frenzy hits Cameroon. http://news.bbc.co.uk/2/ hi/africa/910121.stm. (2000). Accessed: 2017-05-7.

[24] Raul Pertierra, Eduardo Ugarte, Alicia Pinggol, Joel Hernandez, and Nikos Lexis Dacanay. 2002. Txt-ing selves : cellphones and Philippine modernity. De La Salle
University Press Manila. vii, 197 p. : pages.

[25] Agha Ali Raza, Farhan Ul Haq, Zain Tariq, Mansoor Pervaiz, Samia Razaq, Uma Saif, and Roni Rosenfeld. 2013. Job Opportunities Through Entertainment: Virally Spread Speech-based Services for Low-literate Users. In Proceedings of the SIGCHI Conference on Human Factors in Computing Systems (CHI '13). ACM, New York, NY, USA, 2803-2812. https://doi.org/10.1145/2470654.2481389

[26] Rhizomatica. 2017. Rhizomatica. https://www.rhizomatica.org/. (2017). Accessed: 2017-05-7.

[27] Everett M. Rogers. 2003. Diffusion of innovations (5th ed.). Free Press, New York, NY [u.a.]. 576 pages.

[28] Jörgen Sandberg. 2005. How do we justify knowledge produced within interpretive approaches? Organizational research methods 8, 1 (2005), 41-68.

[29] James C. Scott. 1985. Weapons of the weak : everyday forms of peasant resistance. Yale University Press, New Haven.

[30] Thomas N. Smyth, Satish Kumar, Indrani Medhi, and Kentaro Toyama. 2010 Where There's a Will There's a Way: Mobile Media Sharing in Urban India. In Proceedings of the SIGCHI Conference on Human Factors in Computing Systems (CHI '10). ACM, New York, NY, USA, 753-762. https://doi.org/10.1145/1753326.1753436

[31] Sonesh Surana, Rabin Patra, Sergiu Nedevschi, Manuel Ramos, Lakshminarayanan Subramanian, Yahel Ben-David, and Eric Brewer. 2008. Beyond Pilots: Keeping Rural Wireless Networks Alive. In Proceedings of the 5th USENIX Symposium on Networked Systems Design and Implementation (NSDI'08). USENIX Association, Berkeley, CA, USA, 119-132. http://dl.acm.org/citation.cfm?id= 1387589.1387598

[32] Judy van Biljon and Paula Kotzé. 2007. Modelling the Factors That Influence Mobile Phone Adoption. In Proceedings of the 2007 Annual Research Conference of the South African Institute of Computer Scientists and Information Technologists on IT Research in Developing Countries (SAICSIT '07). ACM, New York, NY, USA, 152-161. https://doi.org/10.1145/1292491.1292509

[33] Viswanath Venkatesh, Michael G. Morris, Gordon B. Davis, and Fred D. Davis. 2003. User Acceptance of Information Technology: Toward a Unified View. MIS Quarterly 27, 3 (2003), 425-478. http://www.jstor.org/stable/30036540

[34] Mariya Zheleva, Arghyadip Paul, David L. Johnson, and Elizabeth Belding. 2013. Kwiizya: Local Cellular Network Services in Remote Areas. In Proceeding of the 11th Annual International Conference on Mobile Systems, Applications, and Services (MobiSys '13). ACM, New York, NY, USA, 417-430. https://doi.org/10. $1145 / 2462456.2464458$ 